Check for updates

Cite this: RSC Adv., 2017, 7, 34063

Received 28th March 2017

Accepted 5th June 2017

DOI: $10.1039 / \mathrm{c} 7 \mathrm{ra} 03574 \mathrm{~h}$

rsc.li/rsc-advances

\section{Characterization of biodegradable poly(lactic acid) porous scaffolds prepared using selective enzymatic degradation for tissue engineering}

\begin{abstract}
Ziqi Guo, (D) abc Cheng Yang, ${ }^{\text {bc }}$ Zuping Zhou, bc Shan Chen ${ }^{\star a}$ and Fan Li ${ }^{\star a}$
In this study, poly(lactic acid) (PLA) scaffolds were prepared by selective enzymatic degradation using poly(3-hydrobutyrate-co-4-hydrobutyrate) [P(3HB-CO-4HB)] depolymerase. The porous morphology and properties of the scaffolds were investigated to clarify whether the microstructure of the biomimetic extracellular matrix is suitable for cell proliferation and differentiation. When the $\mathrm{P}(3 \mathrm{HB}-\mathrm{co}-4 \mathrm{HB})$ composition of PLA/P(3HB-CO-4HB) blends was changed from $50 \mathrm{wt} \%$ to $60 \mathrm{wt} \%$, the mean pore diameter of the porous PLA scaffolds increased from $64.15 \mu \mathrm{m}$ to $80.01 \mu \mathrm{m}$, the porosity significantly improved from $68.45 \%$ to $79.88 \%$, and the compressive modulus decreased from $9.34 \mathrm{MPa}$ to $6.94 \mathrm{MPa}$. PLA40 with $60 \% \mathrm{P}(3 \mathrm{HB}-\mathrm{CO}-4 \mathrm{HB})$ blending was used in in vitro degradation and mouse embryo fibroblast (MEF) cell culture tests. The results demonstrated that the PLA scaffolds were degraded completely into harmless products in simulated body fluid (SBF) solution at a slow degradation rate, and the weight loss of the scaffolds could reach $80 \%$ after 8 months of in vitro degradation. Meanwhile, the PLA scaffolds showed the largest swelling value of $157.4 \%$ after immersion in SBF solution for 14 days. Cell viability was determined through scanning electron microscopy (SEM) and 3-(4,5-dimethyl-2-thiazolyl)-2,5-diphenyl2-H-tetrazolium bromide (MTT) tests. The results showed that the PLA scaffolds supported the attachment and growth of MEF cells. Compared with the PLA scaffolds without any modification, the PLA scaffolds modified by poly-L-lysine exhibited a better biocompatibility to MEF cells. These results indicate that selective enzymatic degradation has a potential application in scaffold manufacturing.
\end{abstract}

\section{Introduction}

Tissue engineering (TE) is a multidisciplinary effort to reconstruct functional tissues and organs following trauma, end stage organ failure, and congenital abnormalities. ${ }^{1,2}$ In addition, the limitation of organ and tissue transplantations has driven the development of $\mathrm{TE}^{3-6}$, in which new tissues are created from cultured cells and biomaterials. TE, which involves polymer scaffolds, tissue cells, and stimulation factors, has been widely used as an attractive therapeutic treatment for tissue defects. ${ }^{7,8}$

The major challenges in TE are the preparation of porous scaffolds that can mimic special structures for cell attachment and growth. ${ }^{9,10}$ In general, TE scaffolds possess a complex interconnected porous micro-hole structure that could enhance various cellular functions, such as adhesion, migration, proliferation, differentiation, and tissue morphologies. ${ }^{11-15}$ Porous scaffolds should feature not only suitable mechanical

${ }^{a}$ School of Life Sciences, Northeast Normal University, Changchun, 130024, China. E-mail: chens093@nenu.edu.cn; lif885@nenu.edu.cn

${ }^{b}$ School of Life Sciences, Guangxi Normal University, Guilin, 541004, China

${ }^{c}$ Guangxi Universities Key Laboratory of Stem Cell and Biopharmaceutical Technology, Guangxi Normal University, Guilin 541004, China properties to support tissues at implantation sites but also biocompatible and biodegradable properties with controllable degradation rates. ${ }^{\mathbf{1 6 - 1 8}}$ Scaffolds serve as a replacement to the natural extracellular matrix (ECM) until host cells could repopulate and synthesize a new natural matrix.

In recent years, many biodegradable materials have been used to fabricate TE scaffolds; these materials include poly(lactic acid) (PLA), poly( $\varepsilon$-caprolactone) (PCL), poly(lactide-coglycolide), poly(vinyl alcohol), poly(butylene succinate) (PBS), poly(3-hydrobutyrate) (PHB), and poly(3-hydrobutyrate-co-4hydrobutyrate $)[\mathrm{P}(3 \mathrm{HB}-\mathrm{co}-4 \mathrm{HB})]^{19-25}$. Given its absorbability and non-toxicity, PLA has been approved by the US Food and Drug Administration as a biodegradable and biocompatible polymer for use in human body. PLA scaffolds have been prepared by various methods, such as selective vacuum manufacturing, high-pressure molding, salt leaching, and supercritical fluid technology. ${ }^{26-31}$ Many conventional techniques, including phase separation and particulate leaching, have been used and improved to fabricate PLA scaffolds by removing one or two phases from the multiphase blend. ${ }^{32-35}$ However, these techniques usually demonstrate restricted capabilities to control pore characteristics, avoid toxic chemical reagents, and generate an internal pore network within the scaffolds. Selective enzymatic degradation, in which one phase is removed from 
blends, is an alternative technique to prepare porous scaffolds. ${ }^{36-38}$ Liu $^{39}$ reported that PLA scaffolds could be prepared through the selective enzymatic degradation of PCL. However, whether scaffolds prepared by selective enzymatic degradation could be used in TE has yet to be determined. Although various preparation methods have been developed and improved to fabricate an ideal TE scaffold, a clinically useful tissue scaffold remains undeveloped to date.

In the present study, we fabricated an ideal porous scaffold by selective enzymatic degradation. Depolymerase with the substrate specificity of $\mathrm{P}(3 \mathrm{HB}-\mathrm{co}-4 \mathrm{HB})$ was adopted to degrade and remove $\mathrm{P}(3 \mathrm{HB}-c o-4 \mathrm{HB})$ from $\mathrm{PLA} / \mathrm{P}(3 \mathrm{HB}-c o-4 \mathrm{HB})$ blends, and various porous PLA scaffolds were acquired by changing the ratio of $\mathrm{PLA} / \mathrm{P}(3 \mathrm{HB}-\mathrm{co}-4 \mathrm{HB})$ blend films. The properties and biocompatibility of the scaffolds were evaluated in detail. Results show that selective enzymatic degradation is a promising method to prepare porous scaffolds for TE.

\section{Experimental}

\subsection{Materials}

PLA commercially available from Nature works LLC (USA) was used in this work. It exhibited a weight-average molecular weight of $2.07 \times 10^{5} \mathrm{~g} \mathrm{~mol}^{-1}$ and a polydispersity of 1.74 as determined by gel permeation chromatography (GPC). $\mathrm{P}(3 \mathrm{HB}-$ co-4HB) was provided by Tianjin Guoyun Biotech (Tianjin, China). It exhibited a weight-average molecular weight of $4.97 \times$ $10^{5} \mathrm{~g} \mathrm{~mol}^{-1}$ and a polydispersity of 1.85 (GPC). The $4 \mathrm{HB}$ content in the copolymer was $6.5 \mathrm{~mol} \%$ as determined by ${ }^{1} \mathrm{H}$-nuclear magnetic resonance spectroscopy. $\mathrm{P}(3 \mathrm{HB}-\mathrm{co}-4 \mathrm{HB})$ depolymerase is a novel poly(hydroxybutyrate)-degradable esterase purified from Agrobacterium sp. DSGZ isolated in our laboratory. ${ }^{\mathbf{4 0}}$

\subsection{Blend preparation}

Before processing, PLA and $\mathrm{P}(3 \mathrm{HB}-\mathrm{co}-4 \mathrm{HB})$ were dried at $80{ }^{\circ} \mathrm{C}$ in a vacuum oven for $24 \mathrm{~h}$. PLA $/ \mathrm{P}(3 \mathrm{HB}-\mathrm{co}-4 \mathrm{HB})$ blends at different weight ratios (wt/wt: 10/90, 20/80, 30/70, 40/60, 50/50, $60 / 40,70 / 30,80 / 20,90 / 10)$ were prepared using a Haake batch internal mixer (Haake Rheomix600, Karlsruhe, Germany) with a batch volume of $50 \mathrm{~mL}$. Melt compounding was performed at $175{ }^{\circ} \mathrm{C}$ and a screw speed of $50 \mathrm{rpm}$ for $8 \mathrm{~min}$ until the viscosity had reached a nearly constant value. After mixing, all samples were cut into small pieces, hot-pressed at $180{ }^{\circ} \mathrm{C}$ for $3 \mathrm{~min}$, and then cold-pressed at room temperature to form sheets with a thickness of $0.6 \mathrm{~cm}$ or $0.2 \mathrm{~cm}$. The compression molding steps were carried out carefully to impose the same treatment to each sample.

\subsection{Selective enzymatic degradation}

Selective enzymatic degradation was conducted to remove the $\mathrm{P}(3 \mathrm{HB}-\mathrm{co}-4 \mathrm{HB})$ component from the blends and obtain the corresponding porous PLA scaffolds. The enzymatic degradation of the blends for $\mathrm{P}(3 \mathrm{HB}-\mathrm{co}-4 \mathrm{HB})$ was carried out in phosphate buffer $(\mathrm{pH} 7.5)$ containing $\mathrm{P}(3 \mathrm{HB}-\mathrm{co}-4 \mathrm{HB})$ depolymerase $\left(0.2 \mathrm{mg} \mathrm{mL}^{-1}\right)$ at $50{ }^{\circ} \mathrm{C}$ with shaking at $100 \mathrm{rpm}$, and the enzymatic solution was replaced each $12 \mathrm{~h}$. When the $\mathrm{P}(3 \mathrm{HB}-\mathrm{co}$ -
$4 \mathrm{HB})$ component in the sample was degraded completely, the sample was removed, washed with distilled water, and then dried to constant weight in a vacuum.

\subsection{Morphology analysis}

The appearance of the blends before and after selective enzymatic degradation was obtained using a digital camera, and the microstructure of the PLA scaffolds was observed by scanning electron microscopy (SEM, XL30 ESEM FEG, FEI Co., Eindhoven, The Netherlands). The blends were stored in liquid nitrogen and then brittle fractured. Cryo-fractured surfaces of $\mathrm{PLA} / \mathrm{P}(3 \mathrm{HB}-\mathrm{co}-4 \mathrm{HB})$ blends were observed via SEM to examine the phase structure. Based on the SEM images, the pore diameter and standard deviation were analyzed with an image analysis program (Adobe Photoshop 7.0). 50 random pores on the surface of PLA scaffolds were chosen in each groups to calculate and normalize the pore size. ${ }^{41}$

\subsection{Porosity}

The porosity of the three rectangular cube specimens was determined using Archimedes' principle, and ethanol was used as liquid medium. ${ }^{\mathbf{4 2 4 3}}$ The porosity was calculated via the following equation:

$$
\text { Porosity }(\%)=\left(m_{2}-m_{1}\right) /\left(m_{2}-m_{3}\right) \times 100 \text {, }
$$

where $m_{1}$ is the dry weight of PLA scaffolds, $m_{2}$ is the weight of PLA scaffolds immersed in ethanol, and $m_{3}$ is the weight of PLA scaffolds suspended in ethanol. Three samples were tested to calculate the average porosity.

\subsection{Mechanical properties}

The mechanical properties of the PLA scaffolds $(1.0 \mathrm{~cm} \times 1.0 \mathrm{~cm}$ $\times 0.6 \mathrm{~cm}$ ) were tested in accordance with ISO: $604-02$ by using a universal testing machine (Instron-1121, USA) at room temperature. A crossed speed of $0.2 \mathrm{~mm} \mathrm{~min}^{-1}$ and a $5000 \mathrm{~N}$ load range were used in the mechanical tests. Values were averaged, and the standard deviation of at least three specimens was calculated.

\subsection{In vitro degradation study}

PLA scaffolds were cut into films $(1.0 \mathrm{~cm} \times 1.0 \mathrm{~cm} \times 0.2 \mathrm{~cm})$ for in vitro degradation study. The films were placed in sealed Petri plates containing simulated body fluid (SBF) and then incubated in vitro at $100 \mathrm{rpm}$ and $37^{\circ} \mathrm{C}$. The SBF solution used was reported by Tadashi Kokubo, ${ }^{\mathbf{4 4}}$ and it contained $\mathrm{NaCl}$ (136.8 $\mathrm{mM}), \mathrm{NaHCO}_{3}(4.2 \mathrm{mM}), \mathrm{KCl}(3.0 \mathrm{mM}), \mathrm{K}_{2} \mathrm{HPO}_{4}(1.0 \mathrm{mM})$, $\mathrm{MgCl}_{2} \cdot 6 \mathrm{H}_{2} \mathrm{O}(1.5 \mathrm{mM}), \mathrm{CaCl}_{2}(2.5 \mathrm{mM})$, and $\mathrm{NaSO}_{4}(0.5 \mathrm{mM})$. The $\mathrm{pH}$ of the buffer was adjusted to 7.5 with $\left(\mathrm{CH}_{2} \mathrm{OH}\right)_{3} \mathrm{CNH}_{2}$ and $\mathrm{HCl}$. The SBF solution was replaced every 3 days to avoid any $\mathrm{pH}$ changes that may affect the degradation of the sample. After a predetermined time of in vitro degradation, each blend film was washed with distilled water and then dried in vacuum. Finally, the weight loss of each sample was measured. 


\subsection{Water absorption of the PLA scaffolds}

To ensure that the SBF solution could permeate the porous PLA scaffolds thoroughly, the scaffolds were pre-wetted by SBF solution and then immersed in $50 \mathrm{~mL}$ of SBF solution at $37{ }^{\circ} \mathrm{C}$ for different periods $(7,14,21$, and 28 days). After immersion, the scaffolds were carefully wiped with filter paper to remove the surface water, and then the weights of the scaffolds were measured as $W_{\text {wet }}$. The dry weights of the scaffolds were measured as $W_{\text {dry }}$ before the absorption test.

The water adsorption capacity of the PLA scaffolds was characterized in terms of the swelling percentage $\left(S_{\mathrm{w}}\right)$, which was calculated using the following equation: ${ }^{45}$

$$
S_{\mathrm{w}}=\left(W_{\mathrm{wet}}-W_{\mathrm{dry}}\right) / W_{\text {dry }} \times 100 .
$$

At least three specimens were tested for each sample to obtain an average value.

\subsection{Cell attachment on the PLA scaffolds}

Mouse embryo fibroblast cells purchased from Sigma of Life Science were cultured in Dulbecco's modified Eagle's medium (DMEM, GIBACO, USA) containing 10\% fetal bovine serum (FBS, Hyclone, China) and 1\% antibiotic/antimycotic solution (100 $\mathrm{U} \mathrm{mL}^{-1}$ penicillin and $100 \mu \mathrm{g} \mathrm{mL}^{-1}$ streptomycin, Sigma) at $37{ }^{\circ} \mathrm{C}$ with $5 \%$ humidified $\mathrm{CO}_{2}$. MEF cells were seeded with a density of $1 \times 10^{5}$ cells/sample in a six-well plate containing the PLA scaffolds. Before culturing cells, the PLA scaffolds were sterilized with $75 \%$ ethanol for $1 \mathrm{~h}$, washed with PBS for three times, and then exposed to UV light for $2 \mathrm{~h}$. Sterile PLA scaffolds were immersed in DMEM at $37{ }^{\circ} \mathrm{C}$ with $5 \%$ humidified $\mathrm{CO}_{2}$ for $24 \mathrm{~h}$, and MEF cells $\left(1 \times 10^{5}\right.$ cells per sample $)$ were evenly dropped onto the top of the scaffolds. The cell-seeded PLA scaffolds were cultured at $37^{\circ} \mathrm{C}$ with $5 \%$ humidified $\mathrm{CO}_{2}$ for 1 , 3 , and 7 days, and the medium was replaced every 2 days. The cell-scaffold constructs were fixed in $2.5 \%$ glutaraldehyde for $2 \mathrm{~h}$, dehydrated with a graded series of ethanol solutions $(50 \%$, $70 \%, 80 \%, 90 \%$, and absolute ethanol), dried in vacuum, sputter-coated with gold, and then viewed using SEM. ${ }^{\mathbf{4 6}}$

\subsection{Cell viability}

A 3-(4,5-dimethyl-2-thiazolyl)-2,5-diphenyl-2- $H$-tetrazolium bromide (MTT) test was performed to detect cell viability, which is an indicator to evaluate the cell biocompatibility or cytotoxicity of the PLA scaffolds. The MTT test is a colorimetric assay in which the amount of the pale yellow MTT formazan complex is measured and is directly proportional to the number of living cells. PLA scaffolds were immersed in DMEM containing $10 \%$ FBS and $1 \%$ antibiotic/antimycotic solution at $37^{\circ} \mathrm{C}$ for $12 \mathrm{~h}$, and the conditional DMEM was used to culture MEF cells in 96well plates. A tissue culture plate adding fresh DMEM without PLA scaffolds was used as a positive control. MEF cells at $5 \times$ $10^{4}$ cells per $\mathrm{mL}$ were seeded on a 96-well plate containing 200 $\mu \mathrm{L}$ of DMEM medium. During culture, the medium in each well was replaced every 2 days by the relative medium $(200 \mu \mathrm{L})$. After culturing for 1 , 4, and 7 days, $20 \mu \mathrm{L}$ of MTT solution $(20 \mathrm{mM})$ was added into each well, and then cells were cultured at $37^{\circ} \mathrm{C}$ with $5 \%$ humidified $\mathrm{CO}_{2}$ for $4 \mathrm{~h}$ to allow MTT reduction by mitochondrial dehydrogenase in viable cells. The DMEM medium was replaced with $200 \mu \mathrm{L}$ of dimethyl sulfoxide to solubilize the formazan complex, and then the 96-well plates were slightly vibrated to ensure that the formazan completely dissolved. The UV absorbance of the solution in each well at $490 \mathrm{~nm}$ was measured using a microplate reader. ${ }^{47}$ All MTT tests were performed with three replicates.

\subsection{Surface modification of PLA scaffolds}

Porous PLA scaffolds were prepared by selective enzymatic degradation. PLA60 scaffolds were placed in poly-L-lysine (PLL) solution $\left(1.0 \mathrm{~g} \mathrm{~L}^{-1}\right)$ and then negative pressure exhaust was performed to modify the surfaces of the PLA scaffolds. ${ }^{48}$ The modified PLA scaffolds were autoclaved, and their biocompatibility to MEF cells was investigated. MEF cells were cultured both on PLA60 scaffolds and modified PLA60 scaffolds. After 1, 4 , and 7 days of culture, cell viability was evaluated by MTT test as described above.

\subsection{Statistical analysis}

Quantitative data were presented as mean \pm standard deviation. The statistical analysis for significance between the groups was performed by means of Student's $t$-test using SPSS13.0 software. A confidence level of 95\% $(p<0.05)$ was considered to be statistically significant. Each cell culture experiment was performed in triplicate.

\section{Results and discussion}

\subsection{Preparation of PLA scaffolds}

3.1.1 Phase separation of $\mathrm{PLA} / \mathbf{P}(3 \mathrm{HB}-\mathrm{co}-4 \mathrm{HB})$ blends. The morphologies of blends are strongly influenced by the properties of the polymer in the blends. Thomas et al. ${ }^{\mathbf{4 9 5}}$ have studied the blending of PLA/PHB and PLA/poly (3-hydroxybutyrate-co-3hydroxyvalerate) prepared by melt compounding, and found that the blends are immiscible in any type of compositions. In the present study, dynamic mechanical analysis showed that $\mathrm{PLA} / \mathrm{P}\left(3 \mathrm{HB}-\mathrm{co}^{-4 \mathrm{HB}}\right)$ was an immiscible system with the $\mathrm{P}(3 \mathrm{HB}-$ co-4HB) domains evenly dispersed in the PLA matrix (data not shown). This result provided a possibility to prepare porous biodegradable polyester materials by the removal of one component from the binary phase-separated biodegradable polyester blends using selective enzymatic hydrolysis and subsequent elution of the formed water-soluble oligomers and monomers into the surrounding hydrolysis media.

The phase structures of the PLA/P $(3 \mathrm{HB}-\mathrm{co}-4 \mathrm{HB})$ blends were observed by SEM, and the fracture surface micrographs of the blends with $\mathrm{P}(3 \mathrm{HB}-\mathrm{co}-4 \mathrm{HB})$ compositions are shown in Fig. 1(a and $\mathrm{b})$. The $\mathrm{PLA} / \mathrm{P}(3 \mathrm{HB}-\mathrm{co}-4 \mathrm{HB})$ blends showed co-continuous morphology, and both the blends were immiscible when the $\mathrm{P}(3 \mathrm{HB}-\mathrm{co}-4 \mathrm{HB})$ composition of the blends was changed from 50 $\mathrm{wt} \%$ to $60 \mathrm{wt} \%$.

3.1.2 Selective enzymatic degradation. A series of PLA/ $\mathrm{P}(3 \mathrm{HB}-\mathrm{co}-4 \mathrm{HB})$ blends with a variety of compositions (wt/wt: 10/ 

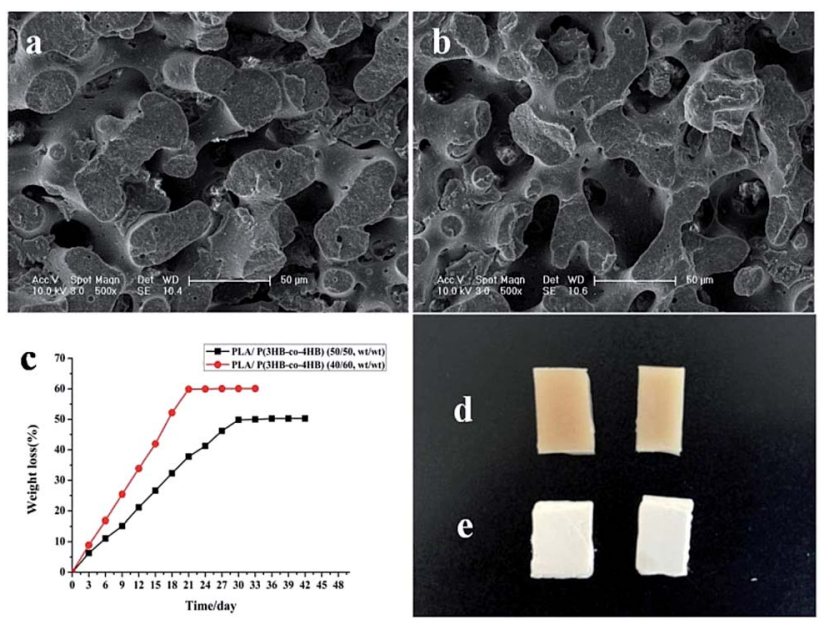

Fig. 1 The change of $\mathrm{PLA} / \mathrm{P}(3 \mathrm{HB}-\mathrm{CO}-4 \mathrm{HB})$ blends via enzymatic degradation: (a) SEM micrographs of the fractured surfaces of blends with the weight ratio (wt/wt, 50/50) after selective enzymatic degradation; (b) SEM micrographs of the fractured surfaces of blends with the weight ratio (wt/wt, 40/60) after selective enzymatic degradation; (c) weight loss curve of the blends; (d) external morphology of PLA/ $\mathrm{P}(3 \mathrm{HB}-\mathrm{CO}-4 \mathrm{HB})$ blends without degradation; (e) external morphology of $\mathrm{PLA} / \mathrm{P}(3 \mathrm{HB}-\mathrm{CO}-4 \mathrm{HB})$ blends after degradation.

$90,20 / 80,30 / 70,40 / 60,50 / 50,60 / 40,70 / 30,80 / 20,90 / 10)$ have been used to prepare porous PLA scaffolds, however, only 50/50 and 60/40 recipes could build stable porous structure and high porosity. Therefore, PLA/P(3HB-co-4HB) blends with the weight ratios (50/50 and 40/60, wt/wt) were prepared by melt blending and hot pressing. $\mathrm{P}(3 \mathrm{HB}-\mathrm{co}-4 \mathrm{HB})$ depolymerase purified from Agrobacterium sp. DSGZ was used to degrade $\mathrm{P}(3 \mathrm{HB}-\mathrm{co}-4 \mathrm{HB})$ in $\mathrm{PLA} / \mathrm{P}(3 \mathrm{HB}-\mathrm{co}-4 \mathrm{HB})$ blends because of its substrate specificity for degrading polyhydroxyalkanoates but not PLA. ${ }^{40}$ As shown in Fig. 1c, the weight loss of the PLA/P(3HB-co-4HB) blends increased with degradation time. The weight loss of the PLA/ $\mathrm{P}(3 \mathrm{HB}-\mathrm{co}-4 \mathrm{HB})$ blends (50/50, wt/wt) reached $49.82 \%$ after 27 days of enzymatic degradation. The weight loss of the PLA/ $\mathrm{P}(3 \mathrm{HB}-\mathrm{co}-4 \mathrm{HB})$ blend films $(40 / 60$, wt/wt) increased to $59.88 \%$ after 21 days of enzymatic degradation. The weight loss remained constant with further degradation, suggesting that the $\mathrm{P}(3 \mathrm{HB}-\mathrm{co}-4 \mathrm{HB})$ component in the blends was completely degraded, and the remaining might be PLA component.

Before enzymatic degradation, the surface of the PLA/P $(3 \mathrm{HB}-$ co-4HB) blends was smooth, and its color was pale yellow. However, the surface of the blends became rougher, and its color turned white after degradation (Fig. 1d and e). With the selective degradation of $\mathrm{P}(3 \mathrm{HB}-\mathrm{co}-4 \mathrm{HB})$, the composition of the scaffolds was mainly PLA, and the color of the scaffolds was white. $\mathrm{P}(3 \mathrm{HB}-\mathrm{co}-4 \mathrm{HB})$ on the surface of the blends was degraded preferentially and then turned gradually to internal until it was completely degraded, which consequently caused its surface to become rough. The rough surface morphology of the PLA scaffolds increased the specific surface area and provided suitable surface properties for cell attachment, proliferation, and migration. According to the composition of PLA in the PLA/ $\mathrm{P}(3 \mathrm{HB}-\mathrm{co}-4 \mathrm{HB})$ blends, the remaining PLA scaffolds were named as PLA40 and PLA50, and the number represented the proportion of PLA in the blends.

\subsection{Morphology of PLA scaffolds}

As illustrated in Fig. 2 and 3, the surface morphologies of the PLA scaffolds prepared by selective enzymatic degradation were observed by SEM. The SEM micrographs of the blends after 15 days of degradation and the remaining PLA scaffolds showed that various pores were distributed evenly onto the surface of the PLA scaffolds. However, the morphology and distribution of the pores significantly differed with the change of the composition of $\mathrm{P}(3 \mathrm{HB}-\mathrm{co}-4 \mathrm{HB})$ in the blends. Through these results we could conclude that polymer composition and degradation time would significantly influence the porous characterizations of the PLA scaffolds via selective enzymatic degradation.

3.2.1 Effect of polymer composition on porous characterizations. As shown in Fig. $2 \mathrm{~d}$ and $3 \mathrm{~d}$, when the $\mathrm{P}(3 \mathrm{HB}-\mathrm{co}-4 \mathrm{HB})$ composition in the blends was increased from $50 \mathrm{wt} \%$ to 60 $\mathrm{wt} \%$, the shape of the pores onto the PLA scaffolds became longer and narrower, and the mean pore diameter increased from $64.15 \pm 1.50$ to $80.01 \pm 1.02 \mu \mathrm{m}$ (Table 1 ). In addition, the porosity of the PLA scaffolds was influenced by the $\mathrm{P}(3 \mathrm{HB}-\mathrm{co}$ $4 \mathrm{HB}$ )/PLA ratio. The porosity in the PLA50 scaffolds was $68.45 \%$, which was lower than the $79.88 \%$ porosity in the PLA40 scaffolds. SEM results showed that pores were distributed regularly onto the surface of the PLA scaffolds when the $\mathrm{P}(3 \mathrm{HB}-$ co-4HB) composition was $50 \mathrm{wt} \%$ or $60 \mathrm{wt} \%$, and then several pores were distributed within the PLA40 scaffolds and PLA50 scaffolds.

Porous TE scaffolds to be used as replacements of injured living tissues must possess optimal pore microstructure and mechanical properties. TE scaffolds with a mean pore size of 20 $\mu \mathrm{m}$ are conducive to fibroblast growth; scaffolds with a mean pore size of $20-125 \mu \mathrm{m}$ are suitable for skin regeneration; ${ }^{\mathbf{5 1 , 5 2}}$ Meanwhile, scaffolds with a mean pore size of $100-250 \mu \mathrm{m}$ favor the regeneration of bone cells. ${ }^{53}$ In the present study, the pore
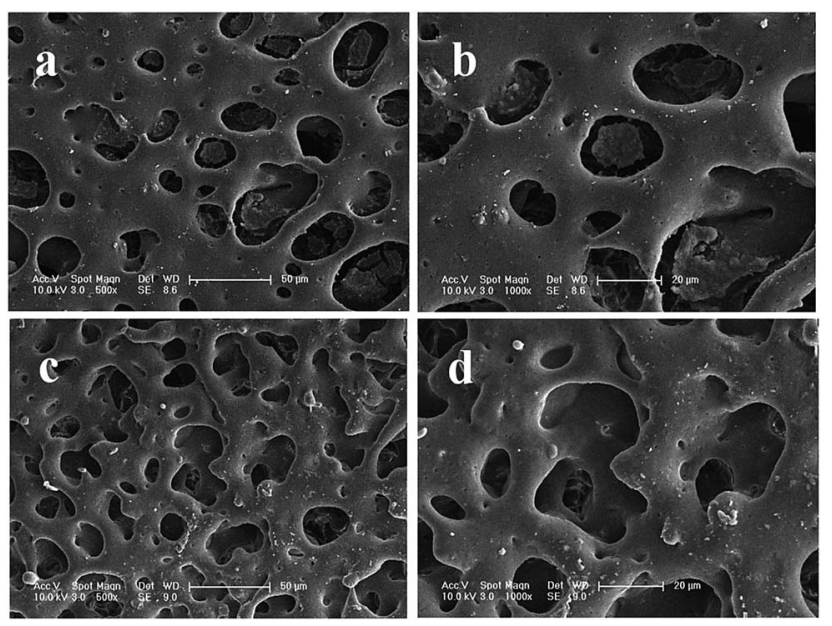

Fig. 2 SEM images of PLA/P(3HB-co-4HB) blends (wt/wt, 50/50) after different degradation times: 15 days of degradation $(a, b), 30$ days of degradation (c, d). 

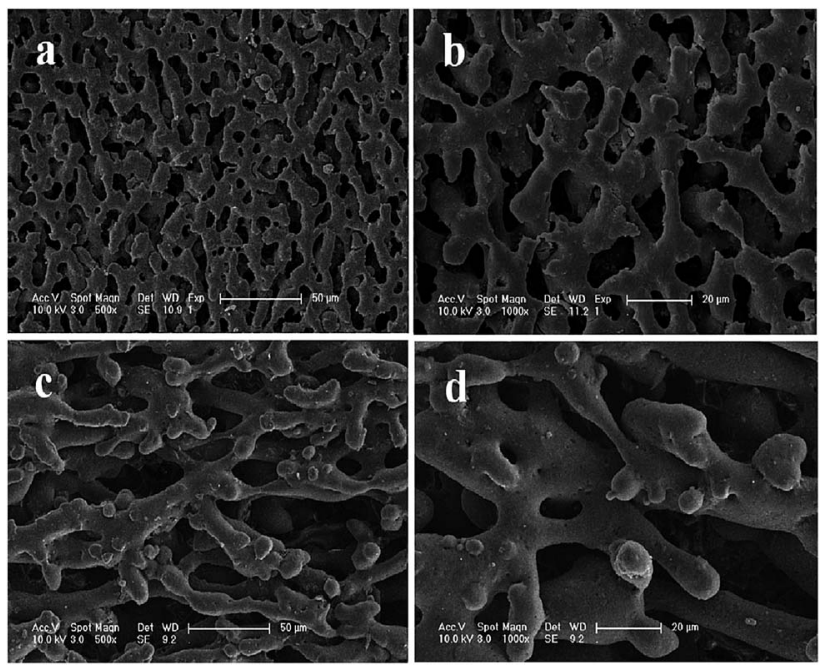

Fig. 3 SEM images of PLA/P(3HB-co-4HB) blends (wt/wt, 40/60) after different degradation times: 15 days of degradation $(a, b), 30$ days of degradation (c, d).

properties (diameter: $80.01 \mu \mathrm{m}$, porosity: 79.88\%), good connectivity of the pore microstructure, and uniform pore distribution on the surface of the PLA scaffolds indicated the suitability of the PLA40 scaffolds' porous properties for soft TE applications.

3.2.2 Effect of degradation time on porous characterizations. $\mathrm{P}(3 \mathrm{HB}-\mathrm{co}-4 \mathrm{HB})$, a biosynthesis and biodegradable polymer with suitable and biocompatibility, is also an alternative for TE scaffolds. The biodegradation products of 3-hydrobutyrate and 4-hydrobutyrate may be common metabolites in higher organisms. ${ }^{54}$ Therefore, before complete degradation, $\mathrm{P}(3 \mathrm{HB}-\mathrm{co}$ $4 \mathrm{HB})$ residue in PLA scaffolds exerts no influence on the biocompatibility of the scaffolds. The effect of degradation time on porous characterizations was investigated. SEM images of the PLA scaffold surface prepared by selective enzymatic degradation for different periods (15 and 30 days) are shown in Fig. 2 and 3. The pore sizes and mean pore diameters were analyzed and are listed in Table 1. Results showed that degradation time significantly influenced the pore sizes and porosities of the scaffolds. After 15 days of degradation, the mean pore size and porosity of the PLA40 scaffolds were $67.27 \mu \mathrm{m}$ and $68.55 \%$, respectively. When selective enzymatic degradation was prolonged to 30 days, the mean pore size and porosity of the PLA60 scaffolds increased to $80.01 \mu \mathrm{m}$ and $79.88 \%$, respectively. This result demonstrated that prolonging the degradation time could effectively improve the porous microstructure and characterizations of PLA scaffolds. To the best of our knowledge,
Table 2 Mechanical properties of PLA scaffolds

\begin{tabular}{lll}
\hline Scaffolds & Compressive load $(\mathrm{MPa})$ & Elastic modulus $(\mathrm{N})$ \\
\hline PLA40 & $6.94 \pm 0.54$ & $398.33 \pm 3.92$ \\
PLA50 & $9.34 \pm 0.23$ & $523.33 \pm 5.81$
\end{tabular}

this study is the first to optimize the morphological parameters of scaffolds prepared by selective enzymatic degradation. The results suggest that selective enzymatic degradation is suitable to prepare multiple porous scaffolds with different porous structures and porosities by controlling the ratio of blending material composition or the time.

In this study, the PLA40 scaffolds prepared through 30 days of degradation by $\mathrm{P}(3 \mathrm{HB}-c o-4 \mathrm{HB})$ depolymerase had high porosity, uniform pore distribution, and good connectivity. Such properties widen the application range of scaffolds in TE. ${ }^{55}$ Therefore, PLA40 scaffolds after absolute degradation were selected in the following experiments.

\subsection{Mechanical properties of PLA scaffolds}

Mechanical tests were successfully conducted, and the obtained compressive load and elastic modulus of the PLA scaffolds were used to confirm the mechanical properties for the three specimens. The compressive elastic modulus and load of the PLA50 scaffolds were $9.34 \pm 0.23 \mathrm{MPa}$ and $523.33 \pm 5.81 \mathrm{~N}$, respectively, which were larger than those of the PLA40 scaffolds (6.94 $\pm 0.54 \mathrm{MPa}$ and $398.33 \pm 3.92 \mathrm{~N}$, respectively) as listed in Table 2. TE scaffolds should have the mechanical strength needed to create a macroporous scaffold that could retain its structure after implantation, particularly in the reconstruction of human tissues. ${ }^{56}$ To achieve a functionally satisfactory implant for practical applications, mechanical properties should be considered in the design of porous scaffolds. Porous scaffolds are suitable for tissue regeneration and organ repair if the compressive modulus of elasticity is between $0.4 \mathrm{MPa}$ and $350 \mathrm{MPa} .{ }^{57,58}$ In this study, the strength and modulus of the PLA scaffolds conform to the basic mechanical property requirements in TE.

\subsection{Swelling behavior of PLA scaffolds}

Swelling behavior is another important index when assessing the application potential of scaffolds in TE because excessive water absorption destroys the morphology of the scaffold while insufficient absorption inhibits cell growth because of the lack of water. ${ }^{59} \mathrm{Gao}^{60}$ reported the standard of water absorption performance and proposed that scaffolds with water swelling values ranging from $120 \%$ to $200 \%$ are qualified for TE. In the

Table 1 Porous properties of PLA scaffolds prepared by selective enzymatic degradation

\begin{tabular}{|c|c|c|c|c|c|}
\hline Scaffolds & Degradation period (day) & Mean size $(\mu \mathrm{m})$ & Porosity (\%) & Minimum pore size $(\mu \mathrm{m})$ & Maximum pore size $(\mu \mathrm{m})$ \\
\hline PLA50 & 30 & $64.15 \pm 1.50$ & $68.45 \pm 0.88$ & 29.49 & 104.79 \\
\hline \multirow[t]{2}{*}{ PLA40 } & 15 & $67.27 \pm 1.22$ & $68.55 \pm 1.71$ & 31.38 & 121.07 \\
\hline & 30 & $80.01 \pm 1.02$ & $79.88 \pm 2.02$ & 44.53 & 113.97 \\
\hline
\end{tabular}


$\mathbf{a}$

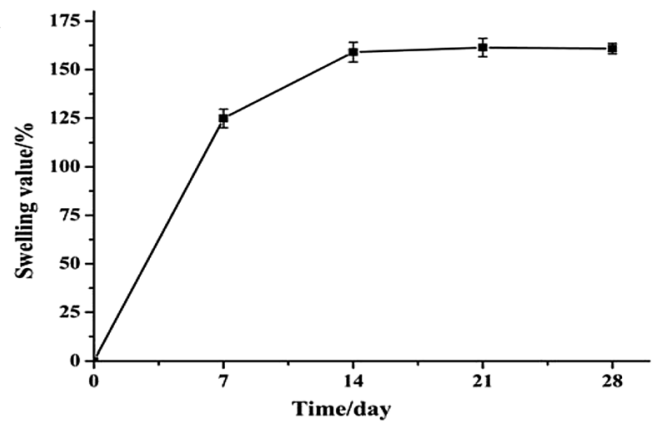

b

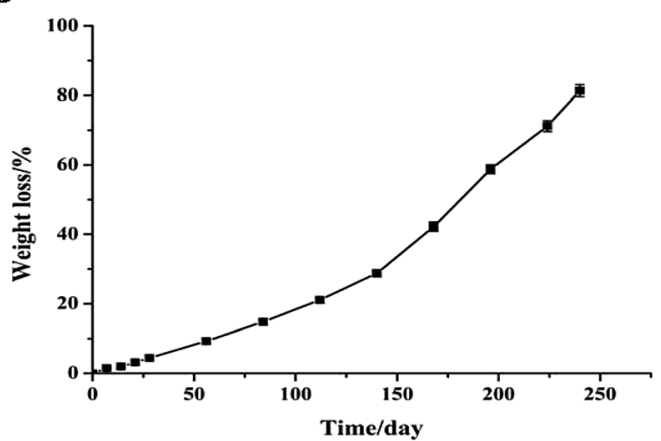

Fig. 4 Swelling behavior (a) and in vitro degradation behavior (b) of PLA scaffolds in SBF solution ( $\mathrm{pH}$ 7.5) at different incubation time intervals.

present study, water absorption was measured to assess the swelling ability of the PLA40 scaffolds. The swelling behavior of the PLA scaffolds in SBF solution is shown in Fig. 4a. After 14 days of immersion in SBF solution, the scaffolds exhibited the largest swelling value (157.4\%) and then became swollen. When the immersion time was prolonged, the swelling value did not change. The results demonstrated that the water absorption of the PLA scaffolds met the standard of TE scaffolds.

\subsection{In vitro degradation of PLA scaffolds}

The in vitro degradation behavior of the PLA scaffolds after immersion in SBF solution at $37{ }^{\circ} \mathrm{C}$ for 240 days is shown in Fig. $4 \mathrm{~b}$. The weight loss of the PLA scaffolds increased with incubation time until the 240th day. After immersion in SBF solution for more than 7 days, more weight loss occurred, and the PLA scaffold (about $150 \mathrm{mg}$ ) was degraded absolutely after 8 months of incubation. Undoubtedly, TE scaffolds should be completely degraded into nontoxic products to cells, but the degradation rate should be slow to allow the scaffolds to maintain their mechanical structure conducive for cell growth. Pushpa and Shi ${ }^{61}$ reported that PLA can be hydrolyzed to carbon dioxide and water under certain conditions. In the present study, the PLA scaffolds could also be hydrolyzed into non-toxic products in vitro, and the good biocompatibility of the PLA scaffolds was not affected by their hydrolysis.

\subsection{Viability of MEF cells on PLA scaffolds}

Biocompatibility is an important characteristic of scaffold materials intended for TE applications. To determine whether the porous PLA scaffolds are suitable for TE applications, MEF cells were seeded on the scaffolds, and the results were investigated by SEM and MTT assay (Fig. 5 and 6).

Fig. 5 displays the SEM images of the PLA scaffolds cultured with 7 days of culture. After culturing, some MEF cells attached onto the surface of the PLA scaffolds. In addition, the majority of MEF cells displayed both scattered single cell and small cell clusters, and exhibited round and spherical morphologies indicating a good cell proliferation. The results demonstrated that MEF cells attached more easily on the surface than in the interior of the PLA40 scaffolds. Cell attachments could be inhibited by bio-polymers with extreme hydrophilicity or hydrophobicity. The morphology of the cells cultured on the scaffolds may be influenced by the hydrophilicity of the TE scaffold materials. ${ }^{47}$ Poisonous reagents were not added in the entire process of preparation, and PLA and $\mathrm{P}(3 \mathrm{HB}-\mathrm{co}-4 \mathrm{HB})$ are medical materials. $\mathrm{P}(3 \mathrm{HB}-c o-4 \mathrm{HB})$ depolymerase could be washed off by sterilized water and $70 \%$ ethanol from the PLA scaffolds. Therefore, non-toxic PLA scaffolds with good biocompatibility through selective enzymatic degradation exhibited a great potential in TE.

In order to further improve PLA40 scaffolds' biocompatibility on cells (adhesion, proliferation, and differentiation), the scaffolds were modified by PLL solution. To investigate the effect of the biocompatibility of PLA40 scaffolds through the modification with PLL solution, the viability of MEF cells on porous scaffolds was measured by MTT assay. Meanwhile, the hydrophilicity of PLA40 scaffolds was tested by using Contact Angle tester. From the hydrophilicity test, we found that PLA40 scaffolds modified by PLL solution showed a better hydrophilicity than unmodified PLA40 scaffolds. As displayed in Fig. 6, MEF cells cultured on PLA40 scaffolds and PLL-modified PLA40 scaffolds showed great proliferative potential, and the cell population significantly increased after 1-4 days of culture. According to these results, we hypothesized the hydrophilicity
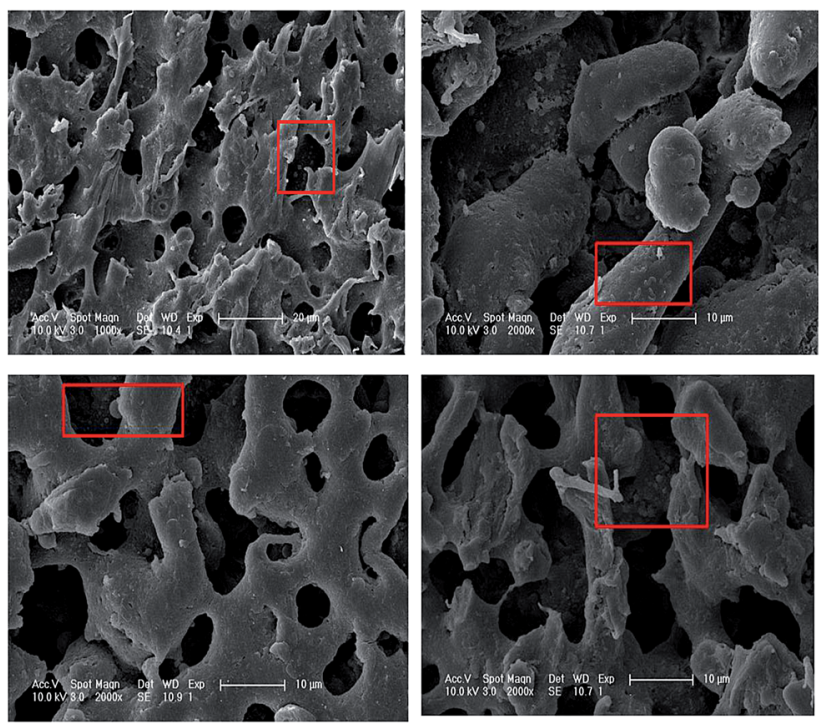

Fig. 5 SEM images of MEF cells on PLA40 scaffolds after 7 days of culture. The red squares indicate adhering cells. 


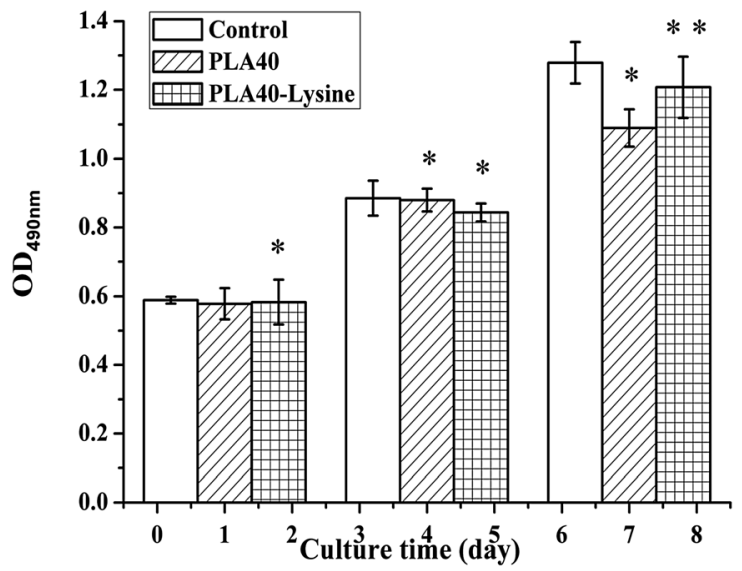

Fig. 6 Cell viability after 1, 4, and 7 days of culture on PLA40 scaffolds and PLL-modified PLA40 scaffolds by MTT assay. Student's $t$-tests were performed on cells on PLA40 scaffolds compared with control cells $(* p<0.05, * * p<0.01)$.

of scaffolds could increase its biocompatibility, and the remaining hydrophobicity of PLA40 scaffolds leaded to a slightly low level of viability compared with the control group cells after 7 days of culture. The viability of MEF cells on the PLL-modified PLA40 scaffolds were significantly higher than those on the PLA40 scaffolds after 7 days of culture, and the results indicated that PLA40 scaffolds' hydrophilicity has been strengthened and then its biocompatibility improved consequently. Compared with the control group, MEF cells' proliferation ability onto PLA40 scaffolds modified by PLL solution kept 90\% after 7 days of culture, therefore we're sure PLA40 scaffolds showed a good biocompatibility. Similar results have previously been observed by Ramakrishna's group ${ }^{62,63}$ using poly(L-lactideco-e-caprolactone)-based scaffolds. According to Yang et al.,${ }^{64}$ an appropriate combination of hydrophobicity/hydrophilicity associated with surface properties remains a substantial factor able to influence cell adhesion and proliferation on biomaterials.

\section{Conclusion}

Novel biomorphic PLA scaffolds were successfully prepared by selective enzymatic degradation. Characteristic tests suggested that porous PLA scaffolds provided good surface and internal structure for cell adhesion and growth. In addition, the mechanical strength, in vitro degradation, and swelling behavior of the PLA scaffolds met the requirements in TE. The blending material composition and degradation time can influence the porous structure of the scaffolds. This advantage renders selective enzymatic degradation applicable in $\mathrm{TE}$ requiring different pore structures.

\section{Acknowledgements}

This work was supported by National Natural Science Foundation of China (No. 31670122) and Scientific and Technological Planning Project of Ji Lin (No. 20150520032JH).

\section{Notes and references}

1 M. Ueda, Tanpakushitsu Kakusan Koso, 2000, 45, 2257-2259.

2 V. Marx, Nature, 2015, 522, 373-377.

3 P. Hernigou, Int. Orthop., 2015, 39, 807-817.

4 J. A. Panadero, L. Vikingsson, J. L. Gomez Ribelles, S. Lanceros-Mendez and V. Sencadas, J. Biomed. Mater. Res., Part B, 2015, 103, 1037-1043.

5 G. A. Mandelaris, D. B. Spagnoli, A. L. Rosenfeld, J. McKee and M. Lu, Int. J. Periodontics Restorative Dent., 2015, 35, 325-333.

6 M. J. Danesh-Meyer, Ann. R. Australas. Coll. Dent. Surg., 2000, 15, 144-149.

7 A. K. Lynn, R. A. Brooks, W. Bonfield and N. Rushton, J. Bone Jt. Surg., Br. Vol., 2004, 86, 1093-1099.

8 M. V. Risbud and M. Sittinger, Trends Biotechnol., 2002, 20, 351-356.

9 Y. K. Kurokawa and S. C. George, Adv. Drug Delivery Rev., 2016, 96, 255-233.

10 O. D. Baydik, M. A. Titarenko and P. G. Sysolyatin, Stomatologiia, 2015, 94, 65-68.

11 A. Panda, Indian J. Urol., 2015, 31, 87-88.

12 X. Zhang and Y. Zhang, Cell Biochem. Biophys., 2015, 72, 777782.

13 G. Jin, G. H. Yang and G. Kim, J. Biomed. Mater. Res., Part B, 2015, 103, 935-948.

14 S. P. Pilipchuk, A. B. Plonka, A. Monje, A. D. Taut, A. Lanis, B. Kang and W. V. Giannobile, Dent. Mater., 2015, 31, 317338.

15 M. Borjigin, C. Eskridge, R. Niamat, B. Strouse, P. Bialk and E. B. Kmiec, Int. J. Nanomed., 2013, 8, 855-864.

16 E. Quinlan, A. Lopez-Noriega, E. Thompson, H. M. Kelly, S. A. Cryan and F. J. O'Brien, J. Controlled Release, 2015, 198, 71-79.

17 X. He, L. Cheng, X. Zhang, Q. Xiao, W. Zhang and C. Lu, Carbohydr. Polym., 2015, 115, 485-493.

$18 \mathrm{~J} . \mathrm{Pu}$ and K. Komvopoulos, Acta Biomater., 2014, 10, 27182726.

19 A. Dogan, S. Demirci, Y. Bayir, Z. Halici, E. Karakus, A. Aydin, E. Cadirci, A. Albayrak, E. Demirci, A. Karaman, A. K. Ayan, C. Gundogdu and F. Sahin, Mater. Sci. Eng., C, 2014, 44, 246-253.

20 M. Zhou and D. Yu, Mol. Med. Rep., 2014, 10, 508-514.

21 A. Przekora, K. Palka and G. Ginalska, J. Biotechnol., 2014, 182-183, 46-53.

22 N. Thadavirul, P. Pavasant and P. Supaphol, J. Biomed. Mater. Res., Part A, 2014, 102, 3379-3392.

23 W. Fu, Z. Liu, B. Feng, R. Hu, X. He, H. Wang, M. Yin, H. Huang, H. Zhang and W. Wang, Int. J. Nanomed., 2014, 9, 2335-2344.

24 C. L. Zhang, K. P. Lv, H. P. Cong and S. H. Yu, Small, 2012, 8, 647-653.

25 K. Mohanraj, S. Sethuraman and U. M. Krishnan, J. Biomed. Mater. Res., Part B, 2013, 101, 840-847.

26 Y. I. Yoon, K. E. Park, S. J. Lee and W. H. Park, BioMed Res. Int., 2013, 2013, 309048. 
27 K. Novotna, M. Zajdlova, T. Suchy, D. Hadraba, F. Lopot, M. Zaloudkova, T. E. Douglas, M. Munzarova, M. Juklickova, D. Stranska, D. Kubies, D. Schaubroeck, S. Wille, L. Balcaen, M. Jarosova, H. Kozak, A. Kromka, Z. Svindrych, V. Lisa, K. Balik and L. Bacakova, J. Biomed. Mater. Res., Part A, 2014, 102, 3918-3930.

28 A. M. Haaparanta, E. Jarvinen, I. F. Cengiz, V. Ella, H. T. Kokkonen, I. Kiviranta and M. Kellomaki, J. Mater. Sci.: Mater. Med., 2014, 25, 1129-1136.

29 C. R. Almeida, T. Serra, M. I. Oliveira, J. A. Planell, M. A. Barbosa and M. Navarro, Acta Biomater., 2014, 10, 613-622.

30 L. G. Santos, D. C. Oliveira, M. S. Santos, L. M. Neves, F. O. de Gaspi, F. A. Mendonca, M. A. Esquisatto, G. M. Santos, M. A. d'Avila and L. H. Mei, J. Nanosci. Nanotechnol., 2013, 13, 4694-4702.

31 S. Roman, A. Mangera, N. I. Osman, A. J. Bullock, C. R. Chapple and S. MacNeil, Neurourol. Urodyn., 2014, 33, 531-537.

32 G. T. Hoffman, E. C. Soller and K. M. McNally-Heintzelman, Biomed. Sci. Instrum., 2002, 38, 53-58.

33 N. K. Mekala, R. R. Baadhe, S. R. Parcha and P. D. Yalavarthy, J. Biomed. Res., 2013, 27, 318-325.

34 R. Scaffaro, F. Lopresti, L. Botta, S. Rigogliuso and G. Ghersi, J. Mech. Behav. Biomed. Mater., 2015, 54, 8-20.

35 X. Zhu, T. Zhong, R. Huang and A. Wan, J. Biomater. Sci., Polym. Ed., 2015, 26, 1286-1296.

36 C. H. Wang, K. R. Fan and G. H. Hsiue, Biomaterials, 2005, 26, 2803-2811.

37 L. M. Pitet, M. A. Amendt and M. A. Hillmyer, J. Am. Chem. Soc., 2010, 132, 8030-8031.

38 L. J. Liu, L. M. Li, G. Henri and V. Michel, Biomacromolecules, 2000, 1, 350-359.

39 T. Hideto and I. Takeharu, Macromol. Biosci., 2001, 1, 59-65.

40 Z. Q. Guo, F. Li, D. Liu, B. H. M. Xia, C. Yang, S. Chen and Y. F. Yang, J. Appl. Polym. Sci., 2015, 133, DOI: 10.1002/ app.42805.

41 H. Liu, S. Wang and N. Qi, J. Appl. Polym. Sci., 2012, 125, E468-E476.

42 N. Johari, M. H. Fathi, M. A. Golozar, E. Erfani and A. Samadikuchaksaraei, J. Mater. Sci.: Mater. Med., 2012, 23, 763-770.

43 B. Pick, M. Pelka, R. Belli, R. R. Braga and U. Lohbauer, Dent. Mater., 2011, 27, 664-669.

44 T. Kokubo and H. Takadama, Biomaterials, 2006, 27, 29072915.
45 N. Kathuria, A. Tripathi, K. K. Kar and A. Kumar, Acta Biomater., 2009, 5, 406-418.

46 J. Qian, X. Yong, W. Xu and X. Jin, Mater. Sci. Eng., C, 2013, 33, 4587-4593.

47 N. M. Alves, J. Shi, E. Oramas, J. L. Santos, H. Tomas and J. F. Mano, J. Biomed. Mater. Res., Part A, 2009, 91, 480-488.

48 R. A. Quirk, W. C. Chan, M. C. Davies, S. J. Tendler and K. M. Shakesheff, Biomaterials, 2001, 22, 865-872.

49 M. Zhang and N. L. Thomas, Adv. Polym. Technol., 2011, 30, 67-79.

50 M. R. Nanda, M. Misra and A. K. Mohanty, Macromol. Mater. Eng., 2011, 296, 719-728.

51 S. S. Kroll, S. Sharma, C. Koutz, H. N. Langstein, G. R. D. Evans, G. L. Robb, D. W. Chang and G. P. Reece, Plast. Reconstr. Surg., 2001, 107, 338-341.

52 S. Sercu, M. Zhang, N. Oyama, U. Hansen, A. E. Ghalbzouri, G. Jun, K. Geentjens, L. Zhang and J. H. Merregaert, J. Invest. Dermatol., 2008, 128, 1397-1408.

53 B. D. Boyan, T. W. Hummert, D. D. Dean and Z. Schwartz, Biomaterials, 1996, 17, 137-146.

54 X. T. Li, Y. Zhang and G. Q. Chen, Biomaterials, 2008, 29, 3720-3728.

55 M. M. Rahman, S. Pervez, B. Nesa and M. A. Khan, Polym. Int., 2013, 62, 79-86.

56 W. L. Grayson, T. P. Martens, G. M. Eng, M. Radisic and G. Vunjak-Novakovic, Semin. Cell Dev. Biol., 2009, 20, 665673.

57 X. H. Wang, S. Shi, G. Guo, S. Z. Fu, M. Fan, F. Luo, X. Zhao, Y. Q. Wei and Z. Y. Qian, J. Biomater. Sci., Polym. Ed., 2011, 22, 1917-1929.

58 C. Zhang, Y. Hu, Z. Xiong, S. Zhang, Y. Yan and F. Cui, Zhongguo Xiufu Chongjian Waike Zazhi, 2005, 19, 100-104.

59 J. Zhang, H.-M. Yin, B. S. Hsiao, G.-J. Zhong and Z.-M. Li, J. Mater. Sci., 2013, 49, 1648-1658.

60 C. Gao, X. Hu, Y. Hong, J. Guan and J. Shen, J. Biomater. Sci., Polym. Ed., 2003, 14, 937-950.

61 P. G. Shao and L. C. Bailey, Pharm. Dev. Technol., 1999, 4, 633-642.

62 M. P. Prabhakaran, J. R. Venugopal and S. Ramakrishna, Biomaterials, 2009, 30, 4996-5003.

63 G. Jin, M. P. Prabhakaran and S. Ramakrishna, Acta Biomater., 2011, 7, 3113-3122.

64 X. Yang, K. Zhao and G. Q. Chen, Biomaterials, 2002, 23, 1391-1397. 